\title{
AMPLIAÇÃO DO ACESSO À JUSTIÇA PARA OS INTERESSADOS DIFUSOS POR MEIO DAS AÇÕES TEMÁTICAS: UM EXAME A PARTIR DO ARCABOUÇO PROCESSUAL DA TRAGÉDIA DE MARIANA/MG
}

\author{
Carlos Alberto Simões de Tomaz ${ }^{1}$ \\ Faustus Máximus de Araujo Alvim ${ }^{2}$
}

\section{Resumo}

O objetivo desta pesquisa é analisar a distinção entre interesse e direito, na perspectiva de Jeremy Bentham, Rudolf Von Ihering, Vicente de Paula Maciel Junior e verificar a contribuição da teoria das ações coletivas como ações temáticas para o acesso à justiça e a participação democrática dos interessados na construção do provimento. $\mathrm{O}$ artigo ampara-se em pesquisa bibliográfica e numa abordagem crítico-dedutiva para verificar que a participação dos interessados através das ações temáticas, amplia o acesso à justiça e as repercussões nos efeitos da sentença coletiva.

Palavras-chave: Acesso à justiça; interesse; direito; ações temáticas.

\section{INCREASED ACCESS TO JUSTICE FOR DIFFUSED STAKEHOLDERS THROUGH THEMATIC ACTIONS: AN EXAMINATION FROM THE PROCEDURAL FRAMEWORK OF THE TRAGEDY OF MARIANA/MG}

\begin{abstract}
The objective of this research is to analyze the distinction between interest and law, from the perspective of Jeremy Bentham, Rudolf Von Ihering, Vicente de Paula Maciel Junior and to verify the contribution of the theory of collective actions as thematic actions for access to justice and the democratic participation of the interested in the construction of the provision. The article is based on bibliographical research and a critical-deductive approach to verify that the participation of the interested parties through the thematic actions, widens the access to justice and the repercussions on the effects of the collective sentence.
\end{abstract}

Keywords: Access to justice; interest; right; thematic actions.

\section{Introdução}

A Constituição da República de 1988, no seu artigo 5ª inciso XXXV, assegura que “a lei não excluirá da apreciação do Poder Judiciário lesão ou ameaça a direito". Veja que o

\footnotetext{
1 Pós-doutor em Filosofia do Direito (Universidade de Coimbra). Doutor em Direito (UNISINOS/RS). Mestre em Direito das Relações Internacionais (UNICEUB). Professor da Graduação e do Programa de Pósgraduação em Direito (Mestrado em proteção dos Direitos Fundamentais) da Universidade de Itaúna, MG. Magistrado.

Mestrado em Proteção dos Direitos Fundamentais pela Universidade de Itaúna/MG. Especialista em Direito Processual (PUC-MG), Gestão Empresarial (PUC-MG) e Finanças Empresariais (FGV). Graduado em Direito, Administração e Ciências Contábeis (PUC-MG). Professor no curso de Direito da Faculdade ASA de Brumadinho e na Academia de Polícia Militar de Minas Gerais. Advogado.
} 
acesso à justiça é um direito fundamental constitucionalizado com aplicação imediata, nos termos do seu artigo $5^{\circ}$, parágrafo $1^{\circ}$. (BRASIL, 1988).

Assim, “o acesso à justiça significa proteção efetiva aos direitos dos governados, e efetividade corresponde à aproximação, tão íntima quanto possível, entre o dever-ser normativo e o ser da realidade social”. (BARROSO, 1993, p. 79).

Nessa perspectiva, o acesso à justiça é um dos pilares de sustentação do Estado Democrático de Direito, sendo indispensável à efetividade dos direitos fundamentais inseridos na Carta Magna Pátria. Sua compreensão não se limita à idéia de simples admissão ao processo ou à possibilidade de ingresso em juízo. A sua efetividade se consubstancia quando os cidadãos conhecem seus direitos lesados e têm condições de superar as barreiras econômicas, sociais e culturais para obterem uma justa reparação e solução do litígio.

"Há que se ter presente que vivemos em um ambiente de pluralismos que repercutem nos campos do direito e da política e de suas institucionalidades. Pluralismos de instâncias, de atores e, em especial, de ordens normativas que dialogam transversal e, muitas vezes, tensionadamente". (MORAIS; BRUM, 2016, p. 62).

Ressalte-se que "a autonomia dos destinatários do ordenamento jurídico somente é garantida na medida em que esses percebem-se também como autores do direito, posto que só tem legitimidade o direito que surge da formação discursiva da opinião e da vontade de cidadãos que possuem os mesmos direitos". (LAGES, 2015, p. 35).

Através de estudo do caso da tragédia ambiental de Mariana/MG, decorrente do rompimento da barragem dos rejeitos de mineração, operada pela Samarco Mineração S.A, pretende-se analisar um dos casos de conflitos de competência para o acesso à justiça, relativo às Ações Civis Públicas ajuizadas na cidade de Governador Valadares/MG, que culminou com a definição, pelo Superior Tribunal de Justiça, da competência definitiva do Juízo da $12^{\text {a }}$ Vara Federal da Seção Judiciária de Minas Gerais, em Belo Horizonte/MG.

Nesse contexto, este estudo tem como objetivo verificar a distinção entre interesse e direito coletivo, examinando o interesse segundo Jeremy Bentham, Rudolf Von Ihering e Vicente de Paula Maciel Junior, e analisar a contribuição da teoria das ações coletivas como ações temáticas, para a participação democrática dos interessados na construção do provimento decisório. 
Esta pesquisa se justifica pela atualidade do tema e sua repercussão, pois envolve o direito fundamental de acesso à justiça na maior tragédia ambiental ainda suportada por um número indeterminado de interessados difusos em nosso País.

O presente trabalho será baseado em pesquisa bibliográfica e com uma abordagem crítico-dedutiva pretende apresentar uma síntese da trajetória processual do Conflito de Competência no 144.922 - MG, suscitado pela Samarco Mineração S/A em face do Juízo de Direito da $7^{\mathrm{a}}$ Vara Cível da Comarca de Governador Valadares/MG e do Juízo da $2^{\mathrm{a}}$ Vara Federal da Subseção Judiciária de Governador Valadares/MG.

Na sequencia, será apresentado um breve conceito sobre a competência da Ação Civil Pública. Na sequencia do estudo, será realizada uma análise sobre o interesse e direito na perspectiva de Jeremy Bentham, Rudolf Von Ihering e de Vicente de Paula Maciel Junior.

No tópico seguinte será analisada a possibilidade de ampliação da participação dos interessados difusos através das ações temáticas. Por fim, serão apresentadas as considerações finais sobre o estudo realizado, reputando que a participação dos interessados na formação do mérito do processo, através das ações temáticas, amplia o acesso à justiça e, consequentemente, as repercussões nos efeitos da sentença coletiva e na extensão da coisa julgada.

\section{A tragédia ambiental de Mariana}

Em 05.11.2015 houve o rompimento da barragem de rejeitos de mineração, denominada "Fundão", localizada no Município de Mariana/MG, operada pela Samarco Mineração S.A. Tal rompimento gerou ondas de rejeitos de minério de ferro e outros particulados, que pela velocidade e volume ocasionaram e continuam causando impactos ambientais e sociais imensuráveis ao longo de toda a bacia hidrográfica do Rio Doce.

O rompimento da barragem de "Fundão" matou dezoito pessoas e deixou uma desaparecida, ocasionando, ainda, o escoamento de milhões de metros cúbicos de lama em direção ao rio Doce até o mar capixaba. No meio do caminho, os rejeitos deixaram centenas de famílias desabrigadas e dezenas de cidades sem abastecimento de água por diversos dias.

O maior desastre ambiental ocorrido no Brasil provocou danos econômicos, sociais e ambientais de expressiva monta. Os prejuízos que se viram às primeiras horas e que aumentaram com o passar do tempo, projetam-se mesmo hoje como um devir que não tem 
tempo certo para findar, pois contemplam danos ambientais, em sua maioria, perenes. Neste contexto, surgiram dezenas de Ações Civis Públicas, em diversas Comarcas no Estado de Minas Gerais, Espírito Santo e no Distrito Federal.

A seguir, será apresentada a síntese da trajetória processual do conflito de competência suscitado pela Samarco Mineração S/A em relação às Ações Civis Públicas aforadas no Juízo Estadual e na Justiça Federal de Governador Valadares/MG, que culminou com a definição, pelo Superior Tribunal de Justiça, da competência do Juízo da $12^{\text {a }}$ Vara Federal da Seção Judiciária de Minas Gerais, em Belo Horizonte/MG.

\subsection{Síntese da trajetória processual do Conflito de Competência $\mathrm{n}^{\circ} 144.922$ - MG suscitado pela Samarco Mineração S/A}

Trata-se de conflito positivo de competência suscitado pela empresa Samarco Mineração S/A, apontando como suscitados o Juízo de Direito da $7^{\text {a }}$ Vara Cível da Comarca de Governador Valadares/MG e o Juízo da $2^{\text {a }}$ Vara Federal da Subseção Judiciária de Governador Valadares/MG. (BRASIL, 2015, p. 6).

Em decorrência do rompimento da barragem de Fundão, em Mariana/MG, o Ministério Público do Estado de Minas Gerais ajuizou Ação Civil Pública Cautelar para a defesa do meio ambiente e da saúde (processo no 0395595-67.2015.8.13.0105) contra a Samarco Mineração S/A, postulando, liminarmente, a imposição de ordem para que fossem fornecidos ao Município de Governador Valadares 800.000 litros de água/dia para a população, 80 carregamentos de caminhões-pipa, 130.000 bombonas de 50 litros por dia para cada uma das 130.000 residências do Município de Governador Valadares, além de outros recursos tendentes a disponibilizar a distribuição de água à população. Apreciando o feito, em 10.11.2015, o Juízo da $7^{\text {a }}$ Vara Cível da Comarca de Governador Valadares/MG deferiu a liminar nos termos pleiteados. (BRASIL, 2015, p. 6).

Paralelamente, a Defensoria Pública da União ajuizou a Ação Civil Pública (processo $n^{o}$ 9362-43.2015.4.01.3813) contra a Samarco e contra a União, especificamente para que a empresa Ré se comprometesse a fornecer, diariamente, no prazo de 24 horas, 553.990 litros de água mineral, até o efetivo retorno do abastecimento de água potável na cidade, sob pena de multa diária no valor de um milhão de reais. O Juízo da $2^{\mathrm{a}}$ Vara Federal da Subsecção Judiciária de Governador Valadares/MG, em 13.11.2015, deferiu o pedido liminar nos termos 
requeridos, determinando, ainda, à União a disponibilização de cem membros das Forças Armadas para atuarem na distribuição de água a ser fornecida pela empresa Ré. (BRASIL, 2015, p. 7).

O juízo da $2^{\text {a }}$ Vara Federal de Governador Valadares, considerando a conexão existente entre as ações e que a tutela pretendida envolve a responsabilidade civil por danos ambientais ao Rio Doce, determinou a remessa dos autos da Ação Civil Pública Estadual. Todavia, o Juízo da $7^{\mathrm{a}}$ Vara Cível da Comarca de Governador Valadares não acatou e manifestou-se de forma contrária à avocação do feito pela Justiça Federal de Governador Valadares. (BRASIL, 2015, p. 7/8).

Considerando a existência de decisões conflitantes entre o Juízo da $7^{\text {a }}$ Vara Cível da Comarca de Governador Valadares e o Juízo da $2^{\text {a }}$ Vara Federal da Subseção Judiciária de Governador Valadares, a Samarco Mineração S/A arguiu o "Conflito de Competência no 144.922 - MG”, sustentando que a competência para jugar estas ações é da Justiça Federal, pois o Rio Doce e os recursos minerais são bens pertencentes à União. Chamado a se manifestar, o Ministério Público Federal opinou pela procedência do conflito, mas para que fosse declarada a competência do Juízo da $12^{\mathrm{a}}$ Vara Federal da Seção Judiciária de Minas Gerais, em Belo Horizonte. (BRASIL, 2015, p. 8).

Em 11.01.2016, a Ministra Laurita Vaz, no exercício da Presidência do Superior Tribunal de Justiça, deferiu parcialmente a liminar pretendida e determinou a suspensão da Ação Cautelar no 0395595-67.2015.8.13.0105 e da Ação Civil Pública no 0426085-72.2015, ambas em trâmite na $7^{\mathrm{a}}$ Vara Cível da Comarca de Governador Valadares/MG e a suspensão da Ação Civil Pública no 9362-43.2015.4.01.3813 em curso na 2a Vara Federal de Governador Valadares/MG, mantendo a eficácia das medidas judiciais já deferidas nesses juízos e designou, provisoriamente, o Juízo Federal da 12a Vara Federal de Belo Horizonte/MG, a fim de decidir medidas urgentes porventura requeridas. (BRASIL, 2015, p. 8/9).

Em 22.06.2016 houve o final do julgamento pela $1^{\text {a }}$ Turma do STJ que, por maioria de votos, conheceu do conflito e declarou competente o Juízo da 12a Vara Federal da Seção Judiciária de Minas Gerais em Belo Horizonte, nos termos do voto da Ministra Relatora ${ }^{3}$. (BRASIL, 2015, p. 1/4).

\footnotetext{
3 DISPOSITIVO: 20. Conflito de competência a que se julga procedente para ratificar a liminar proferida pela Ministra Laurita Vaz, no exercício da Presidência, e determinar a competência definitiva do Juízo da $12^{\mathrm{a}}$ Vara Federal da Seção Judiciária de Minas Gerais, em Belo Horizonte, para apreciar e julgar a causa, determinando a
} 
Não obstante, houve outros incidentes de conflito de competência, como por exemplo, o de n⿳0 146.984 - MG, suscitado pelo Juízo da 12ª Vara Federal da Seção Judiciária de Minas Gerais em relação ao Juízo da $3^{\text {a }}$ Vara Federal Cível da Seção Judiciária do Espírito Santo, a fim de definir a quem compete julgar a Ação Civil Pública ajuizada pelo Ministério Público Federal contra a empresa Samarco Mineração S.A. e distribuída originariamente para a $3^{\text {a }}$ Vara Federal Cível da Seção Judiciária do Espírito Santo, onde o feito tramitou até que foi declinada a competência para o Juízo da $12^{\text {a }}$ Vara da Seção Judiciária de Minas Gerais.

\section{A competência da Ação Civil Pública}

O direito ao meio ambiente, a água, dentre outros, são exemplos de direitos difusos. Tais direitos confundem-se, muitas vezes, com "o interesse da sociedade como um todo. Seus titulares são um número indeterminados de pessoas, ligadas por circunstâncias de fato, como habitarem em uma mesma cidade, desfrutarem de uma mesma paisagem ou dependerem de um mesmo rio para abastecimento de água”. (BARROSO, 2014, p. 212).

A Ação Civil Pública (Lei 7.347/1985), recepcionada pelo artigo 129, inciso III, da Constituição da República de 1988, foi instituída para a tutela jurisdicional de direitos ou interesses difusos, coletivos ou individuais homogêneos, possuindo, ainda, previsão legal do Código de Defesa do Consumidor, Lei 8.078 de 1990. (BRASIL, 1990).

“A Lei da Ação Civil Pública surge como a solução mais adequada para viabilizar o acesso à justiça de dado segmento da sociedade civil para proteção dos interesses difusos mencionados nas leis substantivas”. (LEMOS JUNIOR, 2015, p. 80).

A Ação Civil Pública deverá ser ajuizada no foro do local em que se deu o dano (Lei $\mathrm{n}^{\mathrm{o}}$ 7.347/1985, art. $2^{\circ}$ ). Todavia, havendo interesse da União, suas autarquias e empresas públicas, a competência passará para a Justiça Federal, conforme preceitua o artigo 109, inciso I, da Constituição da República de 1988, mesmo que no local da ocorrência do dano não exista vara da Justiça Federal. (BRASIL, 1985).

remessa da Ação Cautelar n. 0395595-67.2015.8.13.0105 e da Ação Civil Pública n. 0426085-72.2015, ambas em tramitação no Juízo de Direito da $7^{\text {a }}$ Vara Cível da Comarca de Governador Valadares/MG, e da Ação Civil Pública n. 9362-43.2015.4.01.3813, em curso no Juízo da $2^{\mathrm{a}}$ Vara Federal da Subseção Judiciária de Governador Valadares/MG, ficando a critério do Juízo da $12^{\mathrm{a}}$ Vara Federal da Seção Judiciária de Minas Gerais a convalidação dos atos até então praticados. (BRASIL, 2015, p. 1/4). 
"Em se tratando de ação coletiva acerca de dano a consumidores, o entendimento prevalente do STJ é no sentido de que, tendo a lesão ocorrida em mais de uma Comarca, a competência, conforme o caso será do foro da capital do Estado ou do Distrito Federal". (THEODORO JÚNIOR, 2016, p. 927).

Ressalte-se que quando ajuizadas separadamente ações civis públicas de objeto comum, na Justiça Federal e na Estadual, uma vez configurada entre elas a continência, devem ser todas elas reunidas na Justiça Federal, conforme entendimento jurisprudencial já consolidado através da Súmula no 489 do STJ.

Na sequencia deste trabalho será analisado o conceito de interesse e direito coletivo, na perspectiva de Jeremy Bentham, Rudolf Von Ihering e Vicente de Paula Maciel Junior.

\section{Interesse e direito coletivo}

"As exigências de novos direitos surgem somente à vista de novos carecimentos, que, por sua vez, surgem em função da mudança das condições sociais e quando o desenvolvimento técnico permite satisfazê-los". (GUSTIN, 2014, p. 146).

"O direito que assim é experimentado encontra-se determinado por uma função nitidamente simbólica, em que sua autonomia e unidade estão expostas às ingerências da economia e da política". Tais ingerências (da economia e da política) "não impedem que o direito se apresente com uma roupagem de conteúdo democrático, de fundamentabilidade dos direitos humanos e de promessas prestacionais de caráter social". (TOMAZ, 2011a, p. 16).

Não é por menos que "a bandeira da autonomia da vontade nunca foi tão longe içada e nunca serviu de máscara para fertilidade do neo-capitalismo atroz que abarca os interesses de grupos os mais variados que vão desde os detentores dos meios de comunicação aos multiplicadores de capital”. (TOMAZ, 2011b, p. 288).

Ihering ressalta que "nenhum direito, quer o do indivíduo, quer o dos povos, está livre do risco de lesão, porque ao interesse do titular do direito em defendê-lo sempre se contrapõe, na sua esfera, o interesse de outrem em desrespeitá-lo”. (IHERING, 2008, p. 43).

Nessa perspectiva, a palavra direito é empregada em sentido duplo, tanto objetivo como subjetivo. "No sentido objetivo, é o conjunto de leis fundamentais editadas pelo Estado, ou seja, o ordenamento jurídico da vida e, no sentido subjetivo é a atuação concreta da norma abstrata no direito específico de determinada pessoa". (IHERING, 2008, p. 33). 
Veja que os juristas sempre "são chamados a assumir e pôr em relevo as cristalizações culturais subjacentes que consubstanciam o repositório de configurações culturais, experiências, viveres, saberes, enfim, as raízes, o ethos pessoal e coletivo e sua íntima imbricação com as estruturas políticas, sociais e econômicas”. (TOMAZ, 2016, p. 78)

\subsection{Interesse segundo Jeremy Bentham, Rudolf Von Ihering e Vicente de Paula Maciel Junior}

Jeremy Bentham, filósofo e jurista inglês que difundiu o utilitarismo, nasceu em 1748 e faleceu em 1832. Segundo o autor, "a natureza colocou o gênero humano sob o domínio de dois senhores soberanos: a dor e o prazer. Somente a eles compete apontar o que devemos fazer, bem como determinar o que na realidade faremos". (BENTHAM, 1974, p. 9).

"Pelo princípio da utilidade entende-se o princípio que aprova ou desaprova qualquer ação, segundo a sua tendência seja para aumentar ou diminuir a felicidade da parte cujo interesse está em questão ou, em outras palavras que promove ou combate essa felicidade". (BENTHAM, 2000, p. 14). (Tradução livre) ${ }^{4}$

“O interesse do indivíduo está ou não adequado ao princípio da utilidade e serve de critério para se verificar se o ato praticado está cumprindo a finalidade de proporcionar o maior prazer possível”. (BENTHAM, 1974, p. 10)

Já o interesse da comunidade "é a soma dos interesses individuais dos membros que a integram, sendo inútil falar em interesse da comunidade se não se compreender qual é o interesse do indivíduo". (BENTHAM, 1974, p. 10).

A esse respeito, Jeremy Bentham, em sua obra "An Introduction to the Principles of Morals and Legislation" (1781) esclarece que "a comunidade é um corpo fictício, composto das pessoas individuais que são consideradas como constituindo os seus membros. O interesse

\footnotetext{
${ }^{4}$ By the principle of utility is meant that principle which approves or disapproves of every action whatsoever. according to the tendency it appears to have to augment or diminish the happiness of the party whose interest is in question: or, what is the same thing in other words to promote or to oppose that happiness. (BENTHAM, 2000, p. 14).
} 
da comunidade então, o que é? - a soma dos interesses dos vários membros que a compõem”. (BENTHAM, 2000, p. 15). (Tradução livre) ${ }^{5}$.

"Jeremy Bentham considera valoroso apenas o que é útil. Toda sua teoria apoia-se em dois conceitos, situados em lados opostos: dor e prazer. A direção da ação humana deverá ser aquela que busca sempre o máximo de prazer possível”. (PEDRON, 2007, p.31)

Outro autor utilitarista foi o jurista alemão Rudolf Von Ihering, que nasceu em 1818 e faleceu em 1892. Para o autor, o indivíduo existe para si e para a sociedade. (MACIEL JUNIOR, 2006, p. 21). Ihering também define os direitos como interesses juridicamente protegidos. (MACIEL JUNIOR, 2006, p. 23).

"Ihering estruturou todo o seu pensamento de modo a afirmar que qualquer norma deve ser dirigida a um determinado fim ou motivo prático”. (PEDRON, 2007, p. 31).

Segundo Ihering, “o objetivo do direito é a paz. A luta é o meio de consegui-la. Enquanto o direito tiver de repelir o ataque causado pela injustiça - e isso durará enquanto o mundo estiver de pé - ele não será poupado”. (IHERING, 2008, p. 31).

Para o autor, nos casos em que o direito existente tenha seu fundamento em interesses "o novo direito, para impor-se, terá de empenhar-se em luta que, às vezes, se prolonga por séculos e cuja intensidade aumenta quando esses interesses tomam a forma de direitos adquiridos". (IHERING, 2008, p. 36).

O direito, porém, “considerado como concepção teleológica, colocado no meio do mecanismo caótico dos fins, dos anseios e dos interesses humanos, deverá, sem cessar, procurar o melhor caminho e, quando o tiver encontrado, deverá quebrar as barreiras com que se deparar no percurso". (IHERING, 2008, p. 38).

Para Ihering os direitos servem para garantir os interesses da vida, ajudar as suas necessidades e realizar fins. Um direito que por si mesmo possui um valor, pode não tê-lo para outro sujeito. Todo direito estabelecido seria a expressão de um interesse reconhecido pelo legislador e que estaria a merecer a sua proteção. (MACIEL JUNIOR, 2006, p. 22/23).

Vicente de Paula Maciel Junior desenvolveu, em seu pós-doutorado na Universidade de Roma, La Sapienza (2006), pesquisa sobre a "teoria das ações coletivas como ações temáticas”, partindo da reconstrução do conceito de direito e interesse e da classificação dos

\footnotetext{
${ }^{5}$ The community is a fictitious body, composed of the individual persons who are considered as constituting as it were its members. The interest of the community then is, what is it?- the sum of the interests of the several members who compose it. (BENTHAM, 2000, p. 15).
} 
direitos e interesses coletivos. Para o autor, "não podemos partir da perspectiva de Ihering para explicar os novos fenômenos do direito coletivo. O Estado Democrático de Direito nos trouxe como legado a necessidade de vivermos a difusão da racionalidade, que se concretiza por meio de uma infinidade de processos decisórios". (MACIEL JUNIOR, 2006, p. 19).

“A classificação dos interesses e direitos até hoje admitida, baseada na doutrina de Ihering, faz indistintamente menção a eles como uma só coisa. Essa equiparação de conceitos tem impossibilitado a evolução da doutrina no estudo sobre os temas dos direitos coletivos e difusos". (MACIEL JUNIOR, 2006, p. 38).

Para demonstrar a existência de direitos difusos se contrapondo a interesses individuais, o autor apresenta a seguinte hipótese:

\footnotetext{
A entidade estatal de controle ambiental embarga a atividade de uma empresa siderúrgica que polui o meio ambiente e ofende as normas vigentes quanto ao setor. Temos a entidade estatal que atua com poder de polícia, conforme o direito legislado, na tutela das situações jurídicas previstas na norma.

Temos os interessados difusos na qualidade do meio ambiente, que serão atingidos pela poluição no meio ambiente.

Teríamos o interesse da empresa na manutenção de sua atividade comercial, que estaria comprometida e poderia gerar o seu encerramento.

Teríamos ainda os trabalhadores da empresa, que estariam atingidos individualmente em seus interesses de manutenção do emprego. (MACIEL JUNIOR, 2006, p. 38).
}

Nesta hipótese, quais são os interessados? Verifica-se que a entidade estatal (pelo cumprimento de seus fins institucionais), os cidadãos, a sociedade local (atingidos pela poluição ambiental), a empresa (interessada na manutenção de sua atividade comercial) e seus empregados (interessados na manutenção dos empregos). Ainda podemos identificar outros conflitos de interesses de um mesmo grupo, pois o embargo aplicado à atividade que ofende ao meio ambiente objetiva proteger inclusive a saúde dos empregados da empresa, mas eles têm interesse imediato na manutenção do seu emprego. (MACIEL JUNIOR, 2006, p. 38).

Neste caso, haverá um impasse sobre a existência ou não de um direito dos interessados sobre os demais. "Somente após o devido processo legal e a manifestação judicial é que poderemos falar em direito de qualquer dos envolvidos. Deverá haver o necessário processo judicial de validação do interesse para sua transformação em direito". (MACIEL JUNIOR, 2006, p. 39).

"Dentro da perspectiva de Ihering de equiparação de interesses e direitos não poderíamos explicar satisfatoriamente a existência e legitimação de diversos interessados 
perante a norma. Qual ou quais dos interesses manifestados poderiam ser considerados direitos?” (MACIEL JUNIOR, 2006, p. 39).

Qual seria o interesse juridicamente protegido? Ele seria identificável antes mesmo de definido por sentença judicial? Os interesses do dono da fábrica, dos interessados difusos, dos interessados coletivos, da entidade pública, seriam todos equiparados a direito? Mesmo sendo contrapostos? O autor ainda questiona "se o direito é o próprio interesse juridicamente protegido, como admitir que possam existir diversos interesses divergentes na base da formação do direito? Qual seria o momento em que haveria o reconhecimento desses direitos? Eles já decorrem de lei e são auto-executáveis?” (MACIEL JUNIOR, 2006, p. 39).

Para o autor é fundamental distinguir interesse de direito, pois não conseguiremos obter qualquer resposta satisfatória se partirmos da perspectiva de equiparação de interesses e direitos. Assim, “os interesses são manifestações unilaterais de vontade de um sujeito em face de um ou mais bens", e o direito objetivo "é o conjunto de normas abstratamente previstas e vigentes em um determinado país e que formam o seu sistema jurídico, sendo critério de conduta e de análise das situações jurídicas”. (MACIEL JUNIOR, 2006, p. 39).

Diante do conflito de interesses sobre o mesmo bem temos uma situação jurídica que poderá ser resolvida pelos próprios interessados mediante acordo ou por uma sentença judicial. Para o autor, "o direito subjetivo somente existe se há o reconhecimento espontâneo da outra parte ou como a resultante de um processo judicial. Não existem direitos subjetivos prévios diante de um conflito de interesses”. (MACIEL JUNIOR, 2006, p. 41).

Quanto ao direito, pode-se falar em duas espécies: o que resulta de um processo de validação espontânea pela própria sociedade e aquele decorrente de processo judicial perante o Estado-Juiz, que mediante o devido processo legal, legitimará via provimento, o interesse manifestado pela parte. (MACIEL JUNIOR, 2006, p. 42).

Assim, "o equívoco metodológico de Ihering consistiu em pressupor que o interesse somente teria importância para o direito a partir do momento em que houvesse a previsão legal de tutela desse interesse". (MACIEL JUNIOR, 2006, p. 43).

Ressalte-se que "esse equívoco manifestado por Ihering se evidencia mais ainda com a complexidade da evolução da sociedade, que passou a reconhecer direitos que, embora existentes, não eram objeto de cogitação legal”. (MACIEL JUNIOR, 2006, p. 43).

Vicente de Paula Maciel Junior conclui que os interesses e os direitos são conceitos diferentes, mas se inter-relacionam de modo íntimo. “Os interesses são a base a partir da qual 
haverá a manifestação do sujeito e os direitos são as situações jurídicas reconhecidas por um processo de validação de interesses manifestados perante a sociedade ou perante o Estadojuiz”. (MACIEL JUNIOR, 2006, p. 44).

\section{Ampliação da participação dos interessados difusos através das Ações Temáticas}

"É inegável que a demanda coletiva possui uma grande força participativa, mesmo porque o seu resultado poderá gerar modificações e adequações de atos de execução dos agentes políticos no exercício de competências de poder”. (MACIEL JUNIOR, 2006, p. 119).

“O problema da participação, que fundamentalmente decorre da adoção do modelo do Estado Democrático de Direito, está na base da estruturação do processo coletivo. A legitimação para agir é a chave para a compreensão da dimensão desse fenômeno". (MACIEL JUNIOR, 2006, p. 121).

Aroldo Plínio Gonçalves destaca que "o processo se caracteriza como uma 'espécie' do 'gênero' procedimento, pela participação, dos 'interessados', na atividade de preparação do provimento, juntamente com o autor do próprio provimento (o juiz)”. (GONÇALVES, 2012, p. 96).

Por sua vez, "os interessados são aqueles em cuja esfera particular o ato está destinado a produzir efeitos, ou seja, o provimento interferirá de alguma forma, no patrimônio dessas pessoas". (GONÇALVES, 2012, p. 96).

"Nessa perspectiva, o processo começa a se definir pela participação dos interessados no provimento na fase que o prepara, ou seja, no procedimento". "Essa participação, da qual se extrairá o predicado que identifica o processo, é a participação dos interessados em contraditório entre eles". (GONÇALVES, 2012, p. 96).

No atual cenário brasileiro, a legitimidade para agir nas ações coletivas nada mais é do que "a reprodução do modelo da legitimação para agir do processo individual, no qual um sujeito eleito pela norma como o detentor da legitimação representa todos os possíveis interessados e em nome deles atua como um representante adequado daqueles que suportam os efeitos do provimento". (MACIEL JUNIOR, 2006, p. 135).

"Nas ações coletivas para a tutela de direitos difusos é fundamental que haja o reconhecimento da legitimação para agir aos interessados difusos, porque eles na verdade 
são os destinatários do provimento que vão deliberar sobre o bem que diz respeito a todos". (MACIEL JUNIOR, 2006, p. 158).

"Desta forma, a possibilidade de uma tutela ampla e multifacetada é fundamental para garantir uma abordagem completa sobre o bem objeto de tutela em face de um número indeterminado de interessados”. (MACIEL JUNIOR, 2006, p. 159).

"A legitimidade das partes ao processo coletivo se materializa no momento em que são resguardadas no direito de participar da construção e da análise das questões que integram o mérito da pretensão”. (COSTA, 2012, p. 217).

Ressalte-se que "a legitimação do provimento decorrente de uma ação coletiva se dá pelo procedimento que permita a inclusão dos legitimados para a participação na construção da decisão". (MACIEL JUNIOR, 2006, p. 178).

"Reduzir a compreensão do princípio do contraditório à representação dos direitos da coletividade por um representante adequado é retirar dos interessados difusos e coletivos o direito de influir na formação do provimento jurisdicional”. (COSTA, 2012, p. 219).

Esse é o maior desafio da ação coletiva, mas é também a sua essência. Vicente de Paula Maciel Junior sustenta que a ação coletiva deve ser uma ação temática. O autor explica:

\footnotetext{
Entendemos que a ação coletiva deve ser uma demanda que viabilize a discussão de "temas". Esses temas são os fatos ou situações jurídicas que afetam os interessados. Assim, por exemplo, a construção de uma praça pública que gere a destruição de uma grande área verde em um determinado bairro de uma cidade, podendo afetar o manancial de água ou mesmo a qualidade do ar, suscita uma questão ambiental, onde diversos interessados poderão ter entendimentos divergentes sobre a questão. Essa questão ambiental referente a determinado fato concreto de uma cidade será o "tema" da ação coletiva. (MACIEL JUNIOR, 2006, p. 178).
}

Em relação às ações temáticas, Fabrício Veiga Costa destaca que:

As ações temáticas são construções teóricas propostas justamente com o intuito de viabilizar a ressemantização de todo o processo coletivo, a partir de uma concepção democrático-constitucionalizada, cujo fundamento regente se encontra no direito de participação processual de todos os interessados difusos e coletivos quanto à construção discursiva do mérito processual. (COSTA, 2012, p. 221). 
"A ação coletiva deve ser a demanda que propõe um tema, abrindo a possibilidade de que o próprio conteúdo do processo seja definido de modo participativo. O processo coletivo demanda uma fase inicial na qual o seu objeto seja formado". (MACIEL JR, 2006, p. 179).

A finalidade central das ações coletivas como ações temáticas é "oportunizar a instauração de um espaço processualizado em que os interessados poderão controlar os critérios, os fundamentos e as alegações que direcionarão o debate democrático e a construção participada do mérito coletivo”. (COSTA, 2012, p. 224).

Desta forma, "o mérito do processo é construído, dentro de um determinado período de tempo fixado na lei, até quando será possível que os diversos interessados compareçam na demanda e formulem seus pedidos". (MACIEL JUNIOR, 2006, p. 179).

Vicente de Paula Maciel Junior destaca que "quanto maior a participação dos interessados na formação do mérito do processo maior será a possibilidade de que esse processo represente o conflito coletivo de forma ampla". O autor ressalta que esta participação ampliada dos interessados na formação do mérito do processo "é de extrema importância porque terá repercussões nos efeitos da sentença coletiva e na extensão da coisa julgada”. (MACIEL JUNIOR, 2006, p. 179).

"A ação dos diversos interessados difusos deve conduzir a uma possibilidade de ampliação flexível do mérito no processo coletivo". Desta forma, "as ações coletivas não devem ser rígidas quanto à formação do mérito porque se o fato abrange um número indeterminado de interessados é natural que dentre eles existam manifestações de vontade em sentidos diferentes e muitas vezes contraditórios”. (MACIEL JUNIOR, 2006, p. 179).

“A importância da ação coletiva fundada em direito difuso ser temática é que ela trará para o seu bojo um conjunto maior de questões para serem discutidas e terá maiores condições de abranger o conflito pelos diversos ângulos que ele possua". (MACIEL JUNIOR, 2006, p. 181).

Para a formação participada do mérito no processo coletivo, Vicente de Paula Maciel Júnior propõe o estabelecimento de um momento preciso a partir do qual o processo não poderia ser alterado. "Proposta uma ação cuja decisão envolva um bem que afete um número indeterminado de pessoas, o ideal seria que a lei fixasse uma fase de divulgação para que os interessados difusos tomassem ciência e pudessem intervir no processo". (MACIEL JUNIOR, 2006, p. 183). 
Vicente de Paula Maciel Junior reforça que "nas ações coletivas poderia ser estabelecida a obrigatória participação do MP, o que já ampliaria o rol de legitimados presentes na ação e envolveria um órgão que tem por função primordial a defesa da legalidade”. (MACIEL JUNIOR, 2006, p. 183).

"O fato de o legitimado extraordinário deter a capacidade postulatória e poder participar do debate das questões meritórias não excluirá o direito dos demais interessados difusos e coletivos participarem do processo". (COSTA, 2012, p. 217).

"Recebida a defesa e os eventuais aditamentos à inicial, deveria haver um despacho saneador no qual o juiz obrigatoriamente fixasse os pontos controvertidos e o objeto da prova e resolvesse as demais questões do processo". (MACIEL JUNIOR, 2006, p. 183).

“Contra essa decisão poderia ser prevista uma impugnação em prazo razoável (mais ou menos 10 dias), no sentido de permitir a ampliação do objeto da lide ou revisar qualquer equívoco na fixação dos pontos controvertidos”. (MACIEL JUNIOR, 2006, p. 183/184).

O autor assevera que como são vários os interessados difusos, a possibilidade de demandas com objetos diferentes sobre o mesmo bem é uma realidade possível. Todavia, "pior do que haver demandas com decisões contraditórias é não ter qualquer decisão, porque normalmente o objeto de várias demandas coletivas envolve bens de grande relevância social e que não podem ficar sem tutela”. (MACIEL JUNIOR, 2006, p. 184).

Assim, "as ações coletivas como ações temáticas permitem a participação dos legitimados na formação do provimento, resgatando às partes (interessados difusos), o direito de participação em contraditório no processo decisório que os afetará". (MACIEL JUNIOR, 2006, p. 185).

\section{Considerações finais}

Com a tragédia ambiental ocorrida na cidade mineira de Mariana surgiram dezenas de Ações Civis Públicas, em diversas Comarcas, seja em Minas Gerais, no Espírito Santo e no Distrito Federal, acarretando em alguns conflitos de competência, o que culminou com a definição, pelo Superior Tribunal de Justiça, da competência definitiva do Juízo da $12^{\mathrm{a}}$ Vara Federal da Seção Judiciária de Minas Gerais, em Belo Horizonte/MG, para atuar em ações judiciais ligadas à tragédia de Mariana/MG. 
Constatou-se que há distinção entre interesse e direito, principalmente quando se trata dos direitos e interesses difusos. Foi aferido que a proposição de Ihering (o direito como sendo o interesse juridicamente tutelado) vem sendo repetida ao longo dos anos e incorporada na legislação pátria sem uma maior análise crítica de sua validade e de suas consequências no campo do direito. Por sua vez, foi investigada a posição do professor Vicente de Paula Maciel Junior, para quem o interesse é sempre individual, o que nos leva à figura de interessados difusos, que se manifestam acerca de um interesse ligado ao bem tutelado. Nessa perspectiva, verificou-se que os direitos são situações jurídicas reconhecidas seja por um processo de validação de interesses perante a sociedade (reconhecimento espontâneo através do consenso) ou perante o Estado-juiz (através da sentença no processo judicial).

Quanto à teoria das ações coletivas como ações temáticas, verifica-se que a mesma prevê a instauração de um espaço processualizado no qual os interessados poderão, democraticamente, apresentar suas alegações, formular seus pedidos e influir na formação do mérito, participando da construção dialógica do provimento que os afetará.

Acredita-se que com a participação dos interessados na formação do mérito do processo, através das ações temáticas, que contemplem fatos ou situações jurídicas que afetam os interessados, amplia-se o acesso à justiça, as repercussões nos efeitos da sentença coletiva e na extensão da coisa julgada. Diante de tais considerações aposta-se que a participação dos interessados na ação coletiva seja viabilizada através das ações temáticas, mediante procedimento em contraditório entre as partes que sofrerão os efeitos do provimento estatal.

Ressalte-se que a adequação social do direito significa a capacidade de possibilitar a convivência não destrutiva de diversos projetos e perspectivas. E nesse caminho, os (des)acordos encontram-se plantados em questões morais altamente complexas e as respostas sempre de difícil alcance. Tenha-se presente, todavia, que o fiel da balança a dignidade do homem, o homem humano do direito, que deve ser o seu projeto e a partir do qual qualquer interlocução deve ser alçada, para a efetividade dos direitos fundamentais.

\section{Referências}

BARROSO, Luís Roberto. O direito constitucional e a efetividade de suas normas: limites e possibilidades da constituição brasileira. 2. ed. Rio de Janeiro: Renovar, 1993. 
BENTHAM, Jeremy. An Introduction to the Principles of Morals and Legislation. (1781). Kitchener, Canada: Batoche Books, 2000.

BENTHAM, Jeremy. Uma introdução aos princípios da moral e da legislação. São Paulo: Abril, 1974.

BRASIL, 2015. Superior Tribunal de Justiça. Acórdão do Conflito de Competência $n^{o}$ 144.922 - MG. Relat. Min. Diva Malerbi (Desemb. convocada TRF 3 ${ }^{\text {a }}$ R.). Disponível em: $<$ https://ww2.stj.jus.br/processo/revista/documento/mediado/?componente=ITA\&sequencial= $1515902 \&$ num_registro $=201503278588 \&$ data $=20160809 \&$ formato $=P D F>$. Acesso em: 20.02.2017.

BRASIL (1990). Código de Defesa do Consumidor. Lei no 8.078, de 11 de setembro de 1990. RT mini códigos. 17. ed. São Paulo: Revista dos Tribunais, 2015.

BRASIL (1988). Constituição da República Federativa do Brasil de 1.988. 17. ed. São Paulo: Revista dos Tribunais, 2015.

BRASIL (1985). Lei da Ação Civil Pública. Lei no 7.347, de 24 de julho de 1.985. RT mini códigos. 17. ed. São Paulo: Revista dos Tribunais, 2015.

COSTA, Fabrício Veiga. Mérito Processual: a formação participada nas ações coletivas. Belo Horizonte: Arraes, 2012.

GONÇALVES, Aroldo Plínio. Técnica Processual e Teoria do Processo. $2^{\mathrm{a}}$ ed. Belo Horizonte: Del Rey, 2012.

GUSTIN, Miracy Barbosa de Sousa. Das necessidades humanas aos direitos: ensaio de sociologia e filosofia do direito. $2^{\text {a }}$. ed. rev. atual. e ampl. $3^{\text {a }}$ tiragem. Belo Horizonte: Del Rey, 2014.

IHERING, Rudolf Von. A luta pelo Direito. $5^{\mathrm{a}}$ ed. rev. da tradução J. Cretella Jr. e Agnes Cretella. São Paulo: Revista dos Tribunais, 2008.

LAGES, Cintia Garabini. O caráter objetivo dos procedimentos de controle concentrado de constitucionalidade: análise da sua legitimidade. Pará de Minas, MG: Virtual Books, 2016.

LEMOS JUNIOR, Eloy Pereira. Proteção jurídica coletiva dos recursos hídricos: conservação como direito fundamental para as futuras gerações. Belo Horizonte: Arraes, 2015.

LENZA, Pedro. Teoria geral da ação civil pública. São Paulo: Revista dos Tribunais, 2008.

MACIEL JUNIOR, Vicente de Paula. Teoria das ações coletivas: as ações coletivas como ações temáticas. São Paulo: LTr, 2006. 
MORAIS, José Luis Bolzan de; BRUM, Guilherme Valle. Políticas públicas e jurisdição constitucional: entre direitos, deveres e desejos. Porto Alegre: Livraria do Advogado, 2016.

PEDRON, Flávio Quinaud. Direitos e interesses: (re) pensando a relação para além de uma compreensão semântica. Revista do Conselho da Justiça Federal. Brasília: CEJ, ano XI, n.39, p. 30-35, out./dez. 2007.

THEODORO JÚNIOR, Humberto. Curso de Direito Processo Civil: Procedimentos Especiais. vol. II. 50 a ed. rev. atual. e ampl. Rio de Janeiro: Forense, 2016.

THEODORO JÚNIOR, Humberto. Curso de Direito Processual Civil: Teoria geral do direito processual civil, processo de conhecimento e procedimento comum. vol. I. 56 ${ }^{\mathrm{a}}$. ed. rev., atual. e ampl. Rio de Janeiro: Forense, 2015.

TOMAZ (2016), Carlos Alberto Simões de. Constituição, cultura e direitos: o direito constitucional como fio condutor da hermenêutica da dignidade. In: SILVA, Carla Ribeiro Volpini; TOMAZ, Carlos Alberto Simões de. (Coords.). Direito e Cultura na encruzilhada da efetividade dos Direitos Fundamentais. Pará de Minas, MG: Virtual Books, 2016.

TOMAZ (2011a), Carlos Alberto Simões de. Democracia e jurisdição: entre o texto e o contexto. $1^{\text {a }}$. ed. São Paulo: Baraúna, 2011.

TOMAZ (2011b), Carlos Alberto Simões de. A liberdade democrática entre as regras do jogo e o jogo das regras e o discurso pós-moderno da liberdade no fogo cruzado entre a autonomia da vontade e o intervencionismo estatal. Revista Brasileira de Direito Constitucional. $n^{\circ} .17$, p. 277-297, jan./jun. 2011. Disponível em: <http://www.esdc.com.br/ RBDC/RBDC-17/RBDC-17-277-Artigo_Carlos_Alberto_Simoes_de_Tomaz_(A_liberdade_ democratica_entre_as_regras_do_jogo_e_o_jogo_das_regras_e_o_discurso_pos).pdf>. Acesso em: 20.02.2017. 